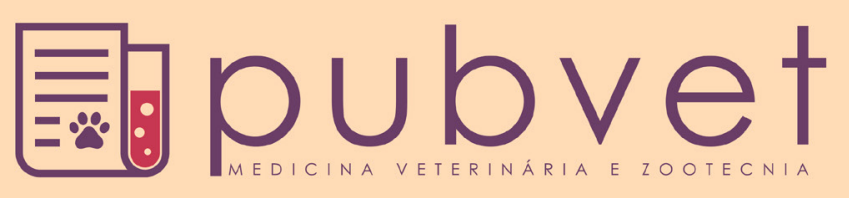

HTTP://DX.DOI.ORG/10.22256/PUBVET.V11N6.638-645

\title{
Rendimento de forragem, composição química e extração de macronutrientes de Trachypogon plumosus consorciado com Stylosanthes capitata cv. Lavradeiro sob níveis de potássio
}

\author{
Newton de Lucena Costa ${ }^{*}$, Anibal de Moraes $^{2}$, Paulo César Faccio de Carvalho ${ }^{3}$, Vicente \\ Gianluppi $^{4}$, João Avelar Magalhães ${ }^{5}$ \\ ${ }^{1}$ Eng. Agr., D.Sc., Embrapa Roraima, Boa Vista, RR. \\ ${ }^{2}$ Professor Adjunto, Departamento de Fitotecnia e Fitossanitarismo da UFPR, Curitiba, PR \\ ${ }^{3}$ Professor Adjunto, Departamento de Plantas Forrageiras e Agrometeorologia da UFRGS, Porto Alegre, RS \\ ${ }^{4}$ Eng. Agr., M.Sc., Embrapa Roraima, Boa Vista, RR. \\ ${ }^{5}$ Med. Veterinário, D.Sc., Embrapa Meio Norte, Parnaiba, PI \\ *Autor para correspondência, E-mail: newton.lucena-costa@embrapa.br
}

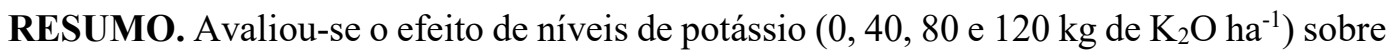
a produtividade de forragem, composição química e extração de macronutrientes de pastagens nativas de Trachypogon plumosus consorciadas com Stylosanthes capitata cv. Lavradeiro nos cerrados de Roraima. Os efeitos da adubação potássica sobre a produtividade de forragem da leguminosa foram diretamente proporcionais aos níveis de $\mathrm{K}$, enquanto que para a gramínea o ajuste foi quadrático e o máximo valor estimado com a

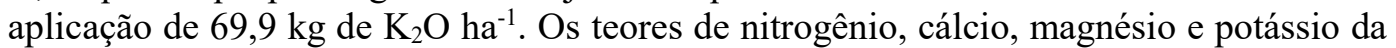
gramínea e leguminosa foram quadraticamente afetados pela adubação potássica, equanto que a extração de macronutrientes pela gramínea a relação foi quadrática e para a leguminosa linear e positiva. As extrações dos macronutrientes pela gramínea e leguminosa, independentemente da adubação potássica, foram maiores para $\mathrm{N}$ e $\mathrm{K}$, seguidas de $\mathrm{Ca}, \mathrm{Mg}$ e P. A adubação potássica proporcionou forragem da gramínea e leguminosa com melhor qualidade e menores teores de fibra. Considerando-se a disponibilidade total de forragem e a composição botânica da pastagem - relação gramínea/leguminosa satisfatória - a utilização de doses de entre 80 e $100 \mathrm{~kg} \mathrm{de}_{2} \mathrm{O}$ ha $^{-1}$ assegura o estabelecimento, a estabilidade produtiva, o fornecimento de forragem de boa qualidade e a persistência da consorciação.
\end{abstract}

Palavras chave: Cálcio, composição botânica, fibra, fósforo, magnésio, matéria seca, nitrogênio, potássio

\section{Forage yield, chemical composition and macronutrient extraction of Trachypogon plumosus pastures intercropping with Stylosanthes capitata cv. Lavradeiro under potassium levels}

ABSTRACT. Was evaluated the effect of potassium fertilization $(0,40,80$ and $120 \mathrm{~kg}$ of $\mathrm{K}_{2} \mathrm{O}$ ha $^{-1}$ ) on the forage yield, chemical composition and macronutrients extraction of Trachypogon plumosus native pastures intercropping with Stylosanthes capitata cv. Lavradeiro in Roraima's savannas. The effects of potassium fertilization on legume forage yield were directly proportional to $\mathrm{K}$ levels, while for grass the adjustment was quadratic and the maximum value estimated with the application of $69.9 \mathrm{~kg}$ of $\mathrm{K}_{2} \mathrm{O} \mathrm{ha}^{-1}$. Nitrogen, calcium, magnesium and potassium contents of the grass and legume were quadratically affected by potassium fertilization, while the macronutrient extraction by the grass was 
quadratic, and linear and positive for forage legume. Macronutrient extractions by grass and legume, independently of potassium fertilization, were higher for $\mathrm{N}$ and $\mathrm{K}$, followed by $\mathrm{Ca}, \mathrm{Mg}$ and $\mathrm{P}$. Potassium fertilization provided grass and legume forage with better quality and lower fiber contents. Considering the overall availability of forage and pasture botanical composition - satisfactory grass/legume relationship - the use of potassium levels between 80 and $100 \mathrm{~kg}$ of $\mathrm{K}_{2} \mathrm{O} \mathrm{ha}{ }^{-1}$ allow the establishment and yield stability and persistence of grass-legume mixture.

Keywords: Botanic composition, calcium, dry matter, fiber, nitrogen, phosphorus, potassium, dry matter

\title{
Rendimiento de forraje, composición química y extracción de macronutrientes de Trachypogon plumosus consorciado con Stylosanthes capitata cv. Lavradeiro bajo niveles de potasio
}

\begin{abstract}
RESUMEN. Se evaluó el efecto de niveles de potasio (0, 40, 80 y $120 \mathrm{~kg}$ de $\mathrm{K}_{2} \mathrm{O}$ ha $\left.\mathrm{a}^{-1}\right)$ sobre la productividad de forraje, composición química y extracción de macronutrientes de pastos nativos de Trachypogon plumosus consorciados con Stylosanthes capitata cv. Labradero en las sabanas de Roraima. Los efectos de la fertilización potásica sobre la productividad del forraje de la leguminosa fueron directamente proporcionales a los niveles de $\mathrm{K}$, mientras que para la gramínea el ajuste fue cuadrático y el máximo valor estimado con la aplicación de $69,9 \mathrm{~kg}$ de $\mathrm{K}_{2} \mathrm{O}$ ha $^{-1}$. Las concentraciones de nitrógeno, calcio, magnesio y potasio de la gramínea y leguminosa fueron cuadráticamente afectadas por la fertilización potásica, mientras que la extracción de macronutrientes por la gramínea la relación fue cuadrática y para la leguminosa lineal y positiva. Las extracciones de los macronutrientes por la gramínea y leguminosa, independientemente de la fertilización potásica, fueron mayores para $\mathrm{N}$ y $\mathrm{K}$, seguidas de $\mathrm{Ca}, \mathrm{Mg}$ y $\mathrm{P}$. La fertilización potásica proporcionó forraje de la gramínea y leguminosa con mejor calidad y menores contenidos de fibra. Considerando la disponibilidad total de forraje y la composición botánica de la pastura - relación gramínea/leguminosa satisfactoria - la utilización de dosis entre 80 y 100 $\mathrm{kg}$ de $\mathrm{K}_{2} \mathrm{O} \mathrm{ha}^{-1}$ asegura el establecimiento, la estabilidad productiva, el suministro de forraje de buena calidad y la persistencia de la consorciación.
\end{abstract}

Palabras clave: Calcio, composición botánica, fibra, fósforo, magnesio, matéria seca, nitrógeno, potasio

\section{Introdução}

A produção de ruminantes em pastagens nativas é uma atividade ecologicamente sustentável, contudo seus baixos índices produtivos expõem a fragilidade econômica do sistema (Pinto et al., 2008). Apesar de limitações quantitativas e qualitativas, decorrentes da baixa fertilidade natural dos solos, historicamente, as pastagens nativas proporcionaram o suporte alimentar para a exploração pecuária, que ao longo dos anos, tornouse uma das principais atividades econômica de Roraima (Costa et al., 2009). O pastoreio contínuo com taxa de lotação variável, mas em geral extensivo e desvinculado do ritmo estacional de crescimento das pastagens, tem contribuição direta para os baixos índices produtivos dos rebanhos (Mata et al., 1996, Sarmiento et al., 2006). O excesso de lotação animal e a não reposição dos nutrientes extraídos constituem as principais causas do esgotamento da fertilidade do solo do ecossistema e, consequentemente, da redução da capacidade de suporte e do potencial produtivo das pastagens nativas ao longo dos anos (Sarmiento, 1992, Ries and Shugart, 2008). Nas áreas planas e não inundáveis dos cerrados, predomina a gramínea Trachypogon plumosus (Humb. \& Bonpl. Ex Willd.) Nees, representando entre 80 e $90 \%$ da composição botânica das pastagens nativas, contudo a produção animal é muito baixa e necessário entre 6 e 10 ha para a manutenção de um bovino adulto, o que inviabiliza economicamente a atividade pecuária, desde que não sejam implementadas práticas de manejo adequadas para o seu melhoramento (Costa et al., 2009).

Para a obtenção de níveis satisfatórios de produção de forragem e, consequentemente do desempenho animal, torna-se necessário a utilização de alguma fonte de nitrogênio $(\mathrm{N})$, 
química ou biológica, já que sua baixa disponibilidade é uma das principais causas da baixa produtividade biológica primária das pastagens nativas (Townsend et al., 2010). A deficiência de $\mathrm{N}$ reflete a diminuição dos teores de matéria orgânica do solo, como consequência do uso frequente das queimadas como prática usual de manejo visando à eliminação da forragem não consumida e senescida. Face aos altos custos dos fertilizantes nitrogenados, a introdução de leguminosas em pastagens nativas, vem sendo recomendada como a alternativa mais eficiente $\mathrm{e}$ econômica para o fornecimento de $\mathrm{N}$ ao sistema solo-planta, além de aumentar a capacidade de suporte, prolongar o período de pastejo e melhorar o valor nutritivo da forragem em oferta (Moreira, 2006, Costa et al., 2013). Dentre as várias leguminosas forrageiras introduzidas e avaliadas em Roraima, Stylosanthes capitata cv. Lavradeiro destacou-se entre as mais promissoras, pois, além de sua excelente produtividade de forragem, bom valor nutritivo e grande capacidade de colonização do solo apresenta boa adaptação a solos de baixa fertilidade natural, alta tolerância à seca e excelente regeneração natural, em decorrência da produção de grandes quantidades de sementes (Costa et al., 2009).

Ensaios exploratórios de fertilidade do solo realizados na Amazônia constataram a baixa disponibilidade de potássio (K), após a do fósforo, como o fator mais limitante ao crescimento de pastagens consorciadas, reduzindo significativamente os rendimentos, a qualidade da forragem e a persistência da leguminosa (Costa et al., 2009). O K tem ação fundamental no metabolismo vegetal, notadamente no processo de fotossíntese, atuando nas reações de transformação da energia luminosa em química, além de participar na síntese de proteínas; neutralização de ácidos orgânicos e na regulação da pressão osmótica e do pH dentro da planta; uso mais eficiente da água, através do melhor controle na abertura e fechamento dos estômatos Costa (2004). Nabinger and Carvalho (2009) recomendam a aplicação de níveis moderados de fertilizantes em pastagens nativas, de modo a favorecer a manutenção e produtividade das espécies de maior interesse forrageiro, evitando o aparecimento e proliferação de espécies oportunistas, beneficiadas momentaneamente pela melhoria do ambiente de produção e que não apresentam, no longo prazo, adaptação às condições edafoclimáticas do ecossistema pastoril.

Neste trabalho foram avaliados os efeitos da adubação potássica sobre a produção de forragem, composição química e extração de macronutrientes por pastagens de Trachyogon plumosus consorciadas com Stylosanthes capitata cv. Lavradeiro, nos cerrados de Roraima.

\section{Material e Métodos}

O ensaio foi conduzido no Campo Experimental da Embrapa Roraima, localizado em Boa Vista, durante o período de junho de 2013 a setembro de 2014 , em uma pastagem nativa onde a gramínea Trachypogon plumosus representava $95 \%$ de sua composição botânica. O clima da região, segundo a classificação de Köppen and Geiger (1928) é Awi, caracterizado por períodos seco e chuvoso bem definidos, com aproximadamente seis meses cada um. A precipitação média anual é de $1.600 \mathrm{~mm}$ e $80 \%$ ocorrem nos seis meses do período chuvoso (abril a setembro). O solo da área experimental é um Latossolo Amarelo, textura média, com as seguintes características químicas, na profundidade de 0-20 cm: $\mathrm{pH}_{\mathrm{H} 2 \mathrm{O}}=4,8 ; \mathrm{P}=1,9 \mathrm{mg} / \mathrm{kg} ; \mathrm{Ca}+\mathrm{Mg}=0,95$ $\mathrm{cmol}_{\mathrm{c}} \cdot \mathrm{dm}^{-3} ; \mathrm{K}=0,01 \mathrm{cmol}_{\mathrm{c}} \cdot \mathrm{dm}^{-3} ; \mathrm{Al}=0,61$ $\mathrm{cmol}_{\mathrm{c}} \mathrm{dm}^{-3} ; \mathrm{H}+\mathrm{Al}=2,64 \mathrm{cmol}_{\mathrm{c}} \cdot \mathrm{dm}^{-3}$ e SB $=0,96$ $\mathrm{cmol}_{\mathrm{c}} \cdot \mathrm{dm}^{-3}$.

O delineamento experimental foi em blocos ao acaso com três repetições. Os tratamentos consistiram de quatro níveis de potássio $(0,40,80$ e $120 \mathrm{~kg} \mathrm{de} \mathrm{K}_{2} \mathrm{O} \mathrm{ha}^{-1}$ ), aplicados a lanço sob a forma de cloreto de potássio. A leguminosa utilizada foi Stylosanthes capitata cv. Lavradeiro, semeada a lanço e sem nenhum revolvimento do solo, após o rebaixamento da pastagem a $10 \mathrm{~cm}$ acima do solo, utilizando-se densidade de semeadura de $3,0 \mathrm{~kg} \mathrm{ha}^{-}$ ${ }^{1}$ de sementes (Valor cultural $=100 \%$ ). O tamanho das parcelas foi de 3,0 × 3,0 m, sendo a área útil de $4,0 \mathrm{~m}^{2}$. A adubação de estabelecimento constou da aplicação de $80 \mathrm{~kg}$ de $\mathrm{P}_{2} \mathrm{O}_{5} \mathrm{ha}^{-1}$, sob a forma de superfosfato triplo, distribuído a lanço quando da semeadura da leguminosa. Durante o período experimental foram realizados seis cortes a intervalos de 56 dias.

Os rendimentos de forragem da gramínea e da leguminosa foram estimados através de cortes mecânicos, realizados a uma altura de $20,0 \mathrm{~cm}$ acima do solo. Em cada avaliação, após a separação dos componentes da consorciação (gramínea e leguminosa), o material colhido foi acondicionado em sacos de papel e pesado para estimativa da produção de biomassa verde e, posteriormente, colocado para secar em estufa de ventilação forçada a $65^{\circ} \mathrm{C}$ por 72 horas para determinação da produção de matéria seca verde (MSV) e moagem em peneira com malha de 5,0 mm. Os teores de nitrogênio $(\mathrm{N})$ 
foram analisados de acordo com procedimentos descritos por Silva and Queiroz (2002); enquanto que os teores de fósforo $(\mathrm{P})$, cálcio $(\mathrm{Ca})$, magnésio $(\mathrm{Mg})$ e potássio $(\mathrm{K})$ foram determinados conforme a metodologia descrita por Silva (2009). Os teores de $\mathrm{P}$ e $\mathrm{K}$ foram quantificados após digestão nitroperclórica. $\mathrm{O} \quad \mathrm{P}$ foi determinado por colorimetria; o K por fotometria de chama e Ca e $\mathrm{Mg}$ por espectrofotometria de absorção atômica. Os teores de fibra em detergente neutro (FDN) e fibra em detergente ácido (FDA) foram determinados pela metodologia proposta por $\underline{V}$ an Soest et al. (1991). A extração dos nutrientes foi estimada multiplicando-se os teores de cada nutriente pela quantidade de forragem acumulada em cada avaliação.

Os dados foram submetidos à análise de variância e de regressão considerando o nível de significância de 5\% de probabilidade, utilizando-se o programa Sisvar (Ferreira, 2011). Para se estimar a resposta dos parâmetros avaliados, em função dos níveis de adubação potássica, a escolha dos modelos de regressão baseou-se na significância dos coeficientes linear e quadrático, por meio do teste " $t$ ", de Student, ao nível de 5\% de probabilidade.

\section{Resultados e Discussão}

Os rendimentos de MSV da leguminosa ( $\mathrm{Y}=$ $\left.800,2+14,68 \mathrm{X} ; \mathrm{R}^{2}=0,96\right)$ e da mistura gramínea + leguminosa $\left(\mathrm{Y}=2.917+17,688 \mathrm{X} ; \mathrm{R}^{2}=0,95\right)$ foram diretamente proporcionais aos níveis de $\mathrm{K}$, enquanto que para a gramínea o efeito foi quadrático $\left(\mathrm{Y}=1.875,1+21,139 \mathrm{X}-0,1511 \mathrm{X}^{2} ; \mathrm{R}^{2}=0,97\right) \mathrm{e}$ o máximo rendimento estimado com a aplicação de $69,9 \mathrm{~kg}$ de $\mathrm{K}_{2} \mathrm{O} \mathrm{ha}^{-1}$ (Tabela 1).

Tabela 1. Rendimento de matéria seca verde (MSV) da gramínea (Trachypogon plumosus), leguminosa (Stylosanthes capitata cv. Lavradeiro) e total (gramínea + leguminosa), em função da adubação potássica

\begin{tabular}{lccc}
\hline Potássio & \multicolumn{3}{c}{ Rendimento de $\mathrm{MSV}^{1}\left(\mathrm{~kg} \mathrm{ha}^{-1}\right)$} \\
\cline { 2 - 4 }$\left(\mathrm{kg} \mathrm{K}_{2} \mathrm{O} \mathrm{ha}^{-1}\right)$ & Gramínea & Leguminosa & Total \\
\hline 0 & 1.879 & 878 & $2.757(31,8)^{*}$ \\
40 & 2.467 & 1.359 & $3.826(35,5)$ \\
80 & 2.611 & 1.798 & $4.409(40,8)$ \\
120 & 2.232 & 2.689 & $4.921(54,6)$ \\
\hline
\end{tabular}

${ }^{1}$ Médias de seis cortes; * Percentual da leguminosa em relação ao rendimento total de matéria seca verde.

Observou-se uma relação inversa entre os componentes da consorciação, pois à medida que os rendimentos de MS da leguminosa foram incrementados, os da gramínea foram reduzidos, evidenciando os efeitos de competição intraespecífica. As leguminosas forrageiras, em decorrência da menor habilidade na absorção de K que as gramíneas, apresentam maior responsividade à sua aplicação, refletindo os efeitos positivos sobre a nodulação e a fixação biológica do nitrogênio. Tendência semelhante foi repostada por Paciullo et al. (2002) para pastagens de Urochloa decumbens, cuja disponibilidade de forragem foi inversamente proporcional à de Stylosanthes guianensis cv. Mineirão. No entanto, Andrade et al. (2003) avaliando a mesma leguminosa, constataram a inviabilidade de sua consorciação $\operatorname{com} U$. decumbens e Urochloa brizantha cv. Marandu, como consequência de sua pequena contribuição para a disponibilidade total de forragem (6,3 e 2,3\%, respectivamente), apesar da adequada disponibilidade de $\mathrm{K}$ no solo $\left(75 \mathrm{mg} \mathrm{kg}^{-1}\right)$.
No manejo de pastagens consorciadas busca-se a estabilidade de sua composição botânica, notadamente, quanto à participação e persistência da leguminosa, considerada como componente mais valioso e instável da consorciação (Andrade et al., 2003, Townsend et al., 2010). Em regiões tropicais, a proporção adequada de leguminosas em pastagens consorciadas está na faixa de 20 a $45 \%$ da disponibilidade total de forragem, visando potencializar os benefícios decorrentes de sua presença, em termos de fixação biológica de $\mathrm{N}$ e maior concentração de nutrientes da forragem em oferta (Thomas, 1992, Ribeiro et al., 2007). A persistência da leguminosa depende diretamente do sistema e da pressão de pastejo utilizadas. Em geral, o pastejo contínuo e o alternado favorecem a permanência das leguminosas e são recomendados como ferramentas de manejo para assegurar sua manutenção na pastagem, considerando-se as variações estacionais da oferta de forragem, notadamente durante o período seco, desde que sejam utilizadas pressões de pastejo compatíveis que assegurem a estabilidade produtiva da 
consorciação (Townsend et al., 2010, Costa et al., 2013).

Os teores de N, P, Ca, Mg e K foram ajustados ao modelo quadrático de regressão e os maiores valores estimados com a aplicação de 82,8; 77,3; 59,$0 ; 60,8$ e 93,6 $\mathrm{kg}$ de $\mathrm{K}_{2} \mathrm{O}$ ha ${ }^{-1}$ para a gramínea e, 66,$2 ; 87,8 ; 79,7 ; 80,1$ e $100,7 \mathrm{~kg}^{-1 e} \mathrm{~K}_{2} \mathrm{O}$ ha $^{-1}$ para a leguminosa, respectivamente (Tabela 2). Com o desenvolvimento do dossel da pastagem o decréscimo na concentração de macronutrientes, reflete o efeito de diluição de seus teores, em função do maior acúmulo de forragem decorrente da adubação potássica. Em pastagens de U. brizantha cv. Marandu consorciadas com Stylosanthes capitata cv. Capica, Costa (2004) reportou maiores teores de $\mathrm{N}, \mathrm{P}, \mathrm{Ca}$ e $\mathrm{Mg}$ da gramínea e leguminosa com a aplicação de doses entre 40 e $80 \mathrm{~kg}$ de $\mathrm{K}_{2} \mathrm{O}$ $\mathrm{ha}^{-1}$, enquanto que as concentrações de $\mathrm{K}$ foram diretamente proporcionais às doses aplicadas $(0,20$, 40,80 e $120 \mathrm{~kg}$ de $\mathrm{K}_{2} \mathrm{O} \mathrm{ha}^{-1}$ ).

Tabela 2. Teores $\left(\mathrm{g} \mathrm{kg}^{-1}\right)$ de nitrogênio $(\mathrm{N})$, fósforo $(\mathrm{P})$, cálcio $(\mathrm{Ca})$, magnésio $(\mathrm{Mg})$ e potássio $(\mathrm{K})$ da gramínea Trachypogon plumosus e da leguminosa Stylosanthes capitata cv. Lavradeiro, em função da adubação potássica. Médias de seis cortes

\begin{tabular}{|c|c|c|c|c|c|}
\hline \multirow[t]{2}{*}{ Variáveis } & \multicolumn{4}{|c|}{ Doses de $\mathrm{K}_{2} \mathrm{O}_{\text {ha }}^{-1}$} & \multirow{2}{*}{ Equação de Regressão } \\
\hline & 0 & 40 & 80 & 120 & \\
\hline & & & & & Gramínea \\
\hline $\mathrm{N}$ & 11,81 & 13,92 & 14,25 & 13,53 & $\mathrm{Y}=11,85+0,0663 \mathrm{X}-0,00043 \mathrm{X}^{2}\left(\mathrm{R}^{2}=0,96\right)$ \\
\hline $\mathrm{P}$ & 1,13 & 1,35 & 1,41 & 1,33 & $\mathrm{Y}=1,13+0,007275 \mathrm{X}-0,000047 \mathrm{X}^{2}\left(\mathrm{R}^{2}=0,93\right)$ \\
\hline $\mathrm{Ca}$ & 3,98 & 4,33 & 4,89 & 4,11 & $\mathrm{Y}=3,91+0,0236 \mathrm{X}-0,00021 \mathrm{X}^{2}\left(\mathrm{R}^{2}=0,89\right)$ \\
\hline $\mathrm{Mg}$ & 1,65 & 1,78 & 1,82 & 1,64 & $\mathrm{Y}=1,64+0,005837 \mathrm{X}-0,000048 \mathrm{X}^{2}\left(\mathrm{R}^{2}=0,92\right)$ \\
\hline \multirow[t]{2}{*}{$\mathrm{K}$} & 9,87 & 11,23 & 13,65 & 12,32 & $\mathrm{Y}=9,62+0,0749 \mathrm{X}-0,00042 \mathrm{X}^{2}\left(\mathrm{R}^{2}=0,89\right)$ \\
\hline & \multicolumn{5}{|r|}{ Leguminosa } \\
\hline $\mathrm{N}$ & 19,87 & 21,45 & 22,81 & 20,65 & $\mathrm{Y}=19,70+0,0794 \mathrm{X}-0,00062 \mathrm{X}^{2}\left(\mathrm{R}^{2}=0,91\right)$ \\
\hline$P$ & 1,52 & 1,73 & 1,85 & 1,79 & $\mathrm{Y}=1,51+0,007387 \mathrm{X}-0,000042\left(\mathrm{R}^{2}=0,95\right)$ \\
\hline $\mathrm{Ca}$ & 5,61 & 6,33 & 6,81 & 6,08 & $\mathrm{Y}=5,56+0,0319 \mathrm{X}-0,00021 \mathrm{X}^{2}\left(\mathrm{R}^{2}=0,92\right)$ \\
\hline $\mathrm{Mg}$ & 2,95 & 3,28 & 3,49 & 3,02 & $\mathrm{Y}=2,92+0,0161 \mathrm{X}-0,00012 \mathrm{X}^{2}\left(\mathrm{R}^{2}=0,93\right)$ \\
\hline $\mathrm{K}$ & 15,19 & 16,89 & 17,21 & 17,88 & $\mathrm{Y}=15,28+0,0403 \mathrm{X}-0,00021 \mathrm{X}^{2}\left(\mathrm{R}^{2}=0,92\right)$ \\
\hline
\end{tabular}

Considerando-se que teores de $\mathrm{N}$ inferiores a $11,2 \mathrm{~g} \mathrm{~kg}^{-1}$ de MS são limitantes para adequada fermentação ruminal, pois resulta em menor consumo voluntário, redução na digestibilidade da forragem e balanço nitrogenado negativo (Minson, 2012) constata-se que a gramínea e a leguminosa atenderiam, satisfatoriamente, aos requerimentos mínimos dos ruminantes, independentemente dos níveis de adubação potássica. Os teores de $\mathrm{Ca}, \mathrm{Mg}$ e K, em todos os níveis de adubação potássica foram superiores ao nível crítico para bovinos de corte em crescimento $\left(1,8 ; 1,0\right.$ e $6,5 \mathrm{~g} \mathrm{~kg}^{-1}$, respectivamente) estipulado pelo NRC (2000); enquanto que para o $\mathrm{P}$ $\left(1,8 \mathrm{~g} \mathrm{~kg}^{-1}\right)$, as exigências seriam atendidas apenas pela leguminosa com a aplicação de $80 \mathrm{~kg}$ de $\mathrm{K}_{2} \mathrm{O}$ $\mathrm{ha}^{-1}$.

A extração de macronutrientes pela leguminosa foi diretamente proporcional aos níveis de $\mathrm{K}$, enquanto que para a gramínea o efeito foi ajustado ao modelo quadrático de regressão e os maiores valores estimados com a aplicação de 71,$1 ; 72,0$;

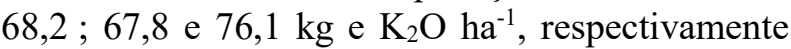

para N, P, Ca, Mg e K (Tabela 3). Os decréscimos na absorção de macronutrientes com o aumento da produtividade de forragem podem decorrer da redução na capacidade fotossintética líquida do dossel, em função do sombreamento mútuo das folhas e da maior taxa respiratória das plantas, com reflexos diretos e negativos sobre as taxas de crescimento, implicando em menor demanda de nutrientes para a o atendimento dos processos metabólicos da gramínea e leguminosa (Lemaire and Agnusdei, 2000, Costa et al., 2010, Lemaire et al., 2011). Costa (2004) constatou que as extrações de $\mathrm{N}, \mathrm{P}, \mathrm{Ca}, \mathrm{Mg}$ e $\mathrm{K}$ foram inversamente proporcionais ao índice de área foliar $\mathrm{e}$ negativamente correlacionadas com a disponibilidade de forragem em pastagens consorciadas de Paspalum atratum cv. Pojuca e Pueraria phaseoloides CIAT-9900. Para assegurar produtividade primária líquida adequada de $T$. plumosus $\left(9.500 \mathrm{~kg}\right.$ de MS ha ${ }^{-1} \mathrm{ano}^{-1}$ ), Medina (1982) e López-Hernández et al. (2006) sugerem como adequadas extrações de $\mathrm{N}$ entre 90 e $113 \mathrm{~kg}$ 
de $\mathrm{N} \mathrm{ha}^{-1}$ ano $^{-1}$, valores inferiores aos constatados neste trabalho. Para todos os macronutrientes, as quantidades extraídas foram superiores às reportadas por Heringer and Jacques (2002) para pastagens nativas do Rio Grande do Sul, sem queima e sem roçada $(41,3 ; 4,5 ; 4,8 ; 4,1$ e $61,1 \mathrm{~kg}$ $\mathrm{ha}^{-1}$, respectivamente para N, P, Ca, Mg e K).

As extrações dos macronutrientes pela gramínea e leguminosa, independentemente da adubação potássica, foram maiores para $\mathrm{N}$ e $\mathrm{K}$, seguidas de
$\mathrm{Ca}, \mathrm{Mg}$ e P (Tabela 2). Esses resultados demonstram a necessidade de reposição dos macronutrientes extraídos visando maximizar a eficiência da adubação potássica, com reflexos positivos e significativos na disponibilidade de forragem da consorciação. Da mesma forma, Costa (2004) reportou efeitos significativos da adubação potássica $\left(30,60,90\right.$ e $120 \mathrm{~kg}$ de $\mathrm{K}_{2} \mathrm{O}$ ha $^{-1}$ ano $\left.^{-1}\right)$ sobre a extração de N, P, Ca, Mg e K por pastagens consorciadas de Paspalum secans e $P$. phaseoloides CIAT-9900.

Tabela 3. Extração $\left(\mathrm{kg} \mathrm{ha}^{-1}\right)$ de nitrogênio $(\mathrm{N})$, fósforo $(\mathrm{P})$, cálcio $(\mathrm{Ca})$, magnésio $(\mathrm{Mg})$ e potássio $(\mathrm{K})$ da gramínea Trachypogon plumosus e da leguminosa Stylosanthes capitata cv. Lavradeiro, em função da adubação potássica. Média de seis cortes.

\begin{tabular}{|c|c|c|c|c|c|}
\hline \multirow{2}{*}{ Variáveis } & \multicolumn{4}{|c|}{ Doses de $\mathrm{K}_{2} \mathrm{O} \mathrm{ha}^{-1}$} & \multirow[t]{2}{*}{ Equação de Regressão } \\
\hline & 0 & 40 & 80 & 120 & \\
\hline & \multicolumn{5}{|c|}{ Gramínea } \\
\hline $\mathrm{N}$ & 133,65 & 206,51 & 223,02 & 186,20 & $\mathrm{Y}=133,5+2,5581 \mathrm{X}-0,0182 \mathrm{X}^{2}\left(\mathrm{R}^{2}=0,89\right)$ \\
\hline $\mathrm{P}$ & 12,73 & 19,98 & 22,08 & 17,81 & $\mathrm{Y}=12,67+0,2593 \mathrm{X}-0,0018 \mathrm{X}^{2}\left(\mathrm{R}^{2}=0,92\right)$ \\
\hline $\mathrm{Ca}$ & 44,87 & 64,09 & 76,60 & 55,04 & $Y=43,50+0,8723 X-0,0064 X^{2}\left(R^{2}=0,94\right)$ \\
\hline $\mathrm{Mg}$ & 18,60 & 26,34 & 28,51 & 21,96 & $\mathrm{Y}=18,44+0,2986 \mathrm{X}-0,0022 \mathrm{X}^{2}\left(\mathrm{R}^{2}=0,93\right)$ \\
\hline \multirow[t]{2}{*}{$\mathrm{K}$} & 111,27 & 166,22 & 213,84 & 164,98 & $\mathrm{Y}=106,8+2,4682 \mathrm{X}-0,0162 \mathrm{X}^{2}\left(\mathrm{R}^{2}=0,91\right)$ \\
\hline & \multicolumn{5}{|r|}{ Leguminosa } \\
\hline $\mathrm{N}$ & 104,67 & 174,90 & 246,07 & 333,16 & $\mathrm{Y}=101,2+1,8916 \mathrm{X}\left(\mathrm{R}^{2}=0,96\right)$ \\
\hline $\mathrm{P}$ & 8,07 & 14,11 & 19,97 & 28,88 & $\mathrm{Y}=7,45+0,1712 \mathrm{X}\left(\mathrm{R}^{2}=0,89\right)$ \\
\hline $\mathrm{Ca}$ & 29,55 & 51,61 & 73,46 & 98,09 & $Y=19,06+0,5687 X\left(R^{2}=0,96\right)$ \\
\hline $\mathrm{Mg}$ & 15,54 & 26,74 & 37,65 & 48,72 & $\mathrm{Y}=15,59+0,2761 \mathrm{X}\left(\mathrm{R}^{2}=0,95\right)$ \\
\hline $\mathrm{K}$ & 80,02 & 137,72 & 185,66 & 288,47 & $\mathrm{Y}=71,97+1,6833 \mathrm{X}\left(\mathrm{R}^{2}=0,90\right)$ \\
\hline
\end{tabular}

Os teores de FDN e FDA da gramínea e leguminosa foram reduzidos com o aumento dos níveis de adubação potássica e ajustados ao modelo linear de regressão (Tabela 4). Costa (2004), para pastagens consorciadas de Paspalum atratum cv. Pojuca com $P$. phaseoloides CIAT-9900 constatou que a aplicação de $80 \mathrm{~kg}$ de $\mathrm{K}_{2} \mathrm{O} \mathrm{ha}^{-1}$ implicou em decréscimos superiores a $10 \%$ nos teores de fibra da gramínea $(78,5$ vs. $71,1 \%$ de FDN e 36,1 vs. $31,9 \%$ de FDA) e da leguminosa (64,2 vs. $57,9 \%$ de FDN e 35,8 vs. $32,2 \%$ de FDA). Nas plantas forrageiras, a adubação ao estimular as taxas de aparecimento e alongamento de folhas afeta positivamente seu comprimento final e a sua duração de vida, contribuindo para a redução ou manutenção dos teores de fibra, apesar dos acréscimos nos níveis de produtividade de forragem (Nussio et al., 1998, Costa et al., 2008, Lemaire et al., 2008, Costa et al., 2013). A proporção dos componentes potencialmente digestíveis tende a diminuir e a de tecidos fibrosos, com o envelhecimento da planta, sendo o conteúdo da parece celular o fator mais limitante ao desempenho produtivo de ruminantes consumindo gramíneas tropicais (Silva and Haridasan, 2007). A FDN, constituída por celulose, hemicelulose, lignina e sílica, afeta diretamente o consumo voluntário, devido a maior taxa de enchimento e a menor taxa de passagem do alimento no sistema digestivo, enquanto que a FDA se correlaciona negativamente com a disponibilidade de energia e a digestibilidade da forragem (Nussio et al., 1998).

Para todos os níveis de adubação potássica, os teores de FDN e FDA da gramínea e os de FDA da leguminosa foram superiores aos limites sugeridos por Van Soest (1994) de 30 e 60\% para FDA e FDN, respectivamente, como indicadores de forragem de alta qualidade, pois forragens com valores de FDA em torno de $40 \%$, ou mais, apresentam acentuada redução no consumo voluntário e na sua digestibilidade. No entanto, os teores foram inferiores aos registrados por Townsend et al. 
(2010) para Axonopus affinis $(79,7 \%$ de FDN e $43,4 \%$ de FDA) e Paspalum dilatatum $(78,2 \%$ de
FDN e $44,5 \%$ de FDA), gramíneas nativas dos cerrados de Rondônia.

Tabela 4. Teores (\%) de fibra em detergente neutro (FDN) e fibra em detergente ácido (FDA) da gramínea Trachypogon plumosus e da leguminosa Stylosanthes capitata cv. Lavradeiro, em função da adubação potássica. Médias de seis cortes

\begin{tabular}{|c|c|c|c|c|c|}
\hline \multirow{2}{*}{ Variáveis } & \multicolumn{4}{|c|}{ Doses de $\mathrm{K}_{2} \mathrm{O}$ ha $^{-1}$} & \multirow{2}{*}{ Equação de Regressão } \\
\hline & 0 & 40 & 80 & 120 & \\
\hline & \multicolumn{5}{|c|}{ Gramínea } \\
\hline FDN & 76,23 & 75,02 & 73,54 & 72,65 & $\mathrm{Y}=76,19-0,0306 \times\left(\mathrm{R}^{2}=0,97\right)$ \\
\hline \multirow[t]{2}{*}{ FDA } & 38,86 & 37,01 & 35,98 & 35,22 & $\mathrm{Y}=38,56-0,0299 \times\left(\mathrm{R}^{2}=0,92\right)$ \\
\hline & \multicolumn{5}{|c|}{ Leguminosa } \\
\hline FDN & 61,43 & 59,33 & 58,27 & 57,88 & $\mathrm{Y}=60,98-0,0293 \times\left(\mathrm{R}^{2}=0,90\right)$ \\
\hline FDA & 35,17 & 33,29 & 33,02 & 32,65 & $\mathrm{Y}=34,71-0,0196 \times\left(\mathrm{R}^{2}=0,85\right)$ \\
\hline
\end{tabular}

\section{Conclusões}

A adubação potássica afeta positivamente o rendimento de forragem, a composição química e a extração de macronutrientes da gramínea e da leguminosa.

As extrações dos macronutrientes pela gramínea e leguminosa, independentemente da adubação potássica, foram maiores para $\mathrm{N}$ e $\mathrm{K}$, seguidas de $\mathrm{Ca}, \mathrm{Mg}$ e $\mathrm{P}$.

A adubação potásica proporciona forragem da gramínea e leguminosa com melhor qualidade e menores teores de fibra.

Considerando-se a disponibilidade total de forragem e a composição botânica da pastagem, a utilização de níveis entre 80 e $100 \mathrm{~kg}$ de $\mathrm{K}_{2} \mathrm{O}$ ha ${ }^{-1}$ permitem o estabelecimento, a estabilidade produtiva, o fornecimento de forragem de boa qualidade e a persistência da consorciação.

\section{Referências Bibliográficas}

Andrade, M. C., Garcia, R., Couto, L., Pereira, O. G. \& Souza, A. 2003. Desempenho de seis gramíneas solteiras ou consorciadas com o Stylosanthes guianensis cv. Mineirão e eucalipto em sistema silvipastoril. Revista Brasileira de Zootecnia, 32, 1845-1850.

Costa, K. A. P., Araujo, J. L., Faquin, V., Oliveira, I. P., Figueiredo, F. C. \& Gomes, K. W. 2008. Extração de macronutrientes pela fitomassa do capim-xaraés "xaraés" em função de doses de nitrogênio e potássio. Ciência Rural, 38, 11621166.

Costa, K. A. P., Oliveira, I. P., Severiano, E. C., Sampaio, F. d. M. T., Carrijo, M. S. \& Rodrigues, C. R. 2010. Extração de nutrientes pela fitomassa de cultivares de Brachiaria brizantha sob doses de nitrogênio. Ciência Animal Brasileira, 11, 307-314.

Costa, N. L. 2004. Formação, manejo e recuperação de pastagens em Rondônia. Porto Velho: Embrapa Rondônia, 217p.

Costa, N. L., Gianluppi, V., Braga, R. M. \& Bendahan, A. B. 2009. Alternativas tecnológicas para a pecuária de Roraima. Boa Vista: Embrapa Roraima, 35p. (Documentos, 19).

Costa, N. L., Moraes, A., Carvalho, P. C. F., Monteiro, A. L. G., Motta, A. C. V. \& Oliveira, R. A. 2013. Composição e extração de nutrientes por Trachypogon plumosus sob adubação e idades de rebrota. Archivos de Sootecnia, 62, 227-238.

Ferreira, D. F. 2011. SISVAR: A Computer Statistical Analysis System. Ciência e Agrotecnologia, 35, 1039-1042.

Heringer, I. \& Jacques, A. V. A. 2002. Qualidade da forragem de pastagem nativa sob distintas alternativas de manejo. Pesquisa Agropecuária Brasileira, 37, 399-406.

Köppen, W. \& Geiger, R. 1928. Klimate der Erde. Gotha: Verlag Justus Perthes. Wall-map $150 \mathrm{~cm} \times 200 \mathrm{~cm}$.

Lemaire, G. \& Agnusdei, M. 2000. Leaf tissue turnover and efficiency of herbage utilization. In: Lemaire, G., Hodgson, J., Moraes, A., Carvalho, P. C. F. \& Nabinger, C. (Eds.) Grassland ecophysiology and grazing ecology. CAB International Publishing, New York.

Lemaire, G., Hodgson, J. \& Chabbi, A. 2011. Grassland productivity and ecosystem services. Cabi, Wallingford. 287p. 
Lemaire, G., Van Oosterom, E., Jeuffroy, M.-H., Gastal, F. \& Massignam, A. 2008. Crop species present different qualitative types of response to $\mathrm{N}$ deficiency during their vegetative growth. Field Crops Research, 105, 253-265.

López-Hernández, D., Santaella, S. \& Chacón, P. 2006. Contribution of nitrogen-fixing organisms to the $\mathrm{N}$ budget in Trachypogon savannas. European Journal of Soil Biology, 42, 43-50.

Mata, D., Herrera, P. \& Birbe, B. 1996. Sistemas de producción animal con bajos insumos para las sabanas de Trachypogon spp. Ecotrópicos, 9, 83100.

Medina, E. 1982. Nitrogen balance in the Trachypogon grasslands of Central Venezuela. Plant and Soil, 67, 305-314.

Minson, D. 2012. Forage in ruminant nutrition. Academic Press, New York.

Moreira, A. L. 2006. Melhoramento de pastagens através da técnica da sobressemeadura de forrageiras de inverno. Pesquisa \& Tecnologia, $3,1-9$.

Nabinger, C. \& Carvalho, P. F. C. 2009. Ecofisiología de sistemas pastoriles: aplicaciones para su sustentabilidad. Agrociencia, 13, 18-27.

NRC. 2000. Nutrient Requirements of Beef Cattle, 7th rev. edn. Natl. Acad. Press, Washington, DC, USA. 242p.

Nussio, L. G., Manzano, R. P. \& Pedreira, C. G. S. 1998. Valor alimentício em plantas do gênero Cynodon. Simpósio sobre Manejo da Pastagem. FEALQ/ESALQ, Piracicaba. p.203-242.

Paciullo, D. S. C., Gomide, J. A., Silva, E. A. M., Queiroz, D. S. \& Gomide, C. A. M. 2002. Características anatômicas da lâmina foliar e do colmo de gramíneas forrageiras tropicais, em função do nível de inserção no perfilho, da idade e da estação de crescimento. Revista Brasileira de Zootecnia, 31, 890-899.

Pinto, C. E., Fontoura Júnior, J. A. S., Frizzo, A., Freitas, T. M. S., Nabinger, C. \& Carvalho, P. C. F. 2008. Produções primária e secundária de uma pastagem natural da Depressão Central do Rio Grande do Sul submetida a diversas ofertas de fitomassa aérea total. Revista Brasileira de Zootecnia, 37, 1737-1741.

Ribeiro, R. C., Rossiello, R. P., Macedo, R. O. \& Barbieri Júnior, E. B. 2007. Introdução de desmódio em pastagem estabelecida de Brachiaria humidicola: densidade e freqüência da leguminosa no consórcio. Revista da Universidade Rural, 27, 41-49.

Ries, L. P. \& Shugart, H. H. 2008. Nutrient limitations on understory grass productivity and carbon assimilation in an African woodland savanna. Journal of Arid Environments, 72, 1423-1430.

Sarmiento, G. 1992. Adaptive strategies of perennial grasses in South American savannas. Journal of Vegetation Science, 3, 325-336.

Sarmiento, G., Silva, M. P., Naranjo, M. E. \& Pinillos, M. 2006. Nitrogen and phosphorus as limiting factors for growth and primary production in a flooded savanna in the Venezuelan Llanos. Journal of Tropical Ecology, 22, 203-212.

Silva, D. J. \& Queiroz, A. C. 2002. Análise de alimentos: métodos químicos e biológicos, $3 \mathrm{Ed}$. Universdiade Federal de Viçosa, Viçosa, Minas Gerais, Brasil. 305p.

Silva, F. C. 2009. Manual de análises químicas de solos, plantas e fertilizantes. Embrapa Informação Tecnológica, Rio de Janeiro. 370p.

Silva, J. S. O. \& Haridasan, M. 2007. Acúmulo de biomassa aérea e concentração de nutrientes em Melinis minutiflora P. Beauv. e gramíneas nativas do cerrado. Revista Brasileira de Botânica, 30, 337-344.

Thomas, R. J. 1992. The role of the legume in the nitrogen cycle of productive and sustainable pastures. Grass and Forage Science, 47, 133142.

Townsend, C. R., Costa, N. L. \& Pereira, A. G. A. 2010. Aspectos econômicos da recuperação de pastagens na Amazônia brasileira. Amazônia: Ciência \& Desenvolvimento, 5, 27-49.

Van Soest, P. J. 1994. Nutritional ecology of the ruminant. Cornell University Press, Ithaca, NY, USA.476p.

Van Soest, P. J., Robertson, J. B. \& Lewis, B. A. 1991. Methods for dietary fiber, neutral detergent fiber, and nonstarch polysaccharides in relation to animal nutrition. Journal of Dairy Science, 74, 3583-3597.

Article History:

Received 15 March 2017

Accepted 17 April 2017

Available on line 2 June 2017

License information: This is an open-access article distributed under the terms of the Creative Commons Attribution License 4.0, which permits unrestricted use, distribution, and reproduction in any medium, provided the original work is properly cited. 